\title{
The Development of a Children's Inventory for Language Learning Strategies (CHILLS)
}

\author{
Assist. Prof. Dr. Esim Gürsoy
}

Uludağ University, Bursa, Turkey

\section{Doi:10.5901/jesr.2013.v3n7p263}

\section{Abstract}

As a widely researched area language learning strategies mostly focused on older learners (adolescents and adults). Language learning strategy research is not complete unless research direction moves towards and deepens in studying language learning strategies (LLS) of children. Previous and limited research on LLS of children focused on a group of strategies and their effects on learning selected language skills. Most of LLS research with children investigated bilingual children, children in immersion classrooms and/or those in ESL contexts. Thus, there is a need for a comprehensive study that investigates strategy use in general, including all strategy groups and their effects on learning all language skills in an EFL context. Another gap in the literature is related to LLS inventories. Some inventories and/or questionnaires that are developed so far investigated strategy use while learning a single skill (such as reading or listening); however, most of these lack reliability and validity data. Some others covered all strategies and provided psychometric information (such as SILL), but none of these are developed for children, yet for children in EFL contexts. Current study aims to develop a language learning strategy inventory for children, by using data collected from 383 fourth and fifth grade (10-11 years old) primary school children in an EFL context. Thus, the study reports on the reliability and validity processes of the instrument. As a result, a valid and reliable inventory for children's language learning strategies (CHILLS: Children's Inventory for Language Learning) is developed.

Keywords: language learning strategies, young learners, strategy inventory, foreign language learning

\section{Introduction}

Teaching English to Young Learners (TEYL) is a still growing area. As soon as TEYL has been supported by the European Commission and Council of Europe in the 1980s and 1990s, many countries increased their attempts to lower the age for foreign language learning (FLL) (Johnstone, 2009). During the past decade TEYL has spread out to many Asian countries such as India, China, Taiwan, etc. (Johnstone, 2009). In Europe, starting language education in preschool or primary school is supported by the EU and the governments are encouraged to do so (Enever \& Moon, 2009). The interest in teaching young learners (YLS) has also triggered research into finding the most appropriate ways to teach YLs. Identification of the differences of children from adults was the starting point of methodological and pedagogical work in TEYL. Children having limited cognitive abilities, world, conceptual, and linguistic knowledge are different from adults in terms of their learning needs. In addition, children's characteristics are also one of the concerns of the researchers and educators in trying to find out the ways relevant to YL's skills and abilities.

According to Piaget, children younger than 11 lack abstract thinking as they are assumed to be in the period of concrete operations (Dworetzky, 1993). Therefore, they can reason within the "here and now" (Arıkan, 2012; Gürsoy, 2012a). Children cannot think of the hypothetical future and do not care much about the past. In addition, children learn fast but also forget fast. They can learn if the information is presented indirectly. They have lower affective filters (Gürsoy \& Akın, 2013; Moon, 2000), and are enthusiastic and talkative (Halliwell, 1992; Moon, 2000). They rely mostly on adults, and like to please them (Moon, 2000). More importantly, unlike adults they do not have a reason for learning another language (Gürsoy, 2012b)

Due to some of the children's characteristics and their developmental features they need to be supported by their teachers not only to facilitate their language learning (LL) process but also to pave the way for autonomous learning. The shift from teacher-centered approaches to learner-centered approaches (Rubin, 1987; Zhao, 2009), which is backed-up by the Council of Europe (2004) has led the attention of educators to the learner.

Developing autonomous learners is one of the components of learner-centered approaches. Autonomy, as a concept, first entered to the language teaching field through a project called "Council of Europe's Modern Languages Project", which was established in 1971. "Autonomy, or the capacity to take charge of one's own learning, was seen as a natural product of the practice of self-directed learning, or learning in which the objectives, progress and evaluation of learning are determined by the learners themselves" (Benson, 2001, p. 8). Self-directed learning, on the other hand, is 
defined by Cohen (1990, p. 10) as an approach in which "learners make decisions, alone or with the help of others, about what they need or want to know, how they will set objectives for learning, what resources and strategies they will use, and how they will assess their progress".

McDonough (2001) brings in a new terminology called "self-regulation", which hasn't been used in the foreign language $(\mathrm{FL})$ terminology, yet related to more common concepts such as self-directed learning, self-instruction or autonomy. Corno and Mandidach (1983) argue that cognitive and affective processes, which are used to complete academic tasks successfully, are planned and monitored through self-regulation. Self-regulation can become automatic when these metacognitive processes, planning and monitoring, is well developed.

Hsiao and Oxford (2002) argue that self-regulation in psychology and autonomy in L2 is closely related. As with psychologists, FL educators see language learning strategies (LLS) as an integral part of self-regulated or self-directed learning. Accordingly, L2 learner autonomy involves: "a) willingness to perform a language task with little or no assistance, with flexibility according to situation, and with transferability to other contexts; and b) relevant action, including the use of appropriate L2 learning strategies for accomplishing the task" (Hsiao and Oxford 2002, p. 369). Using LLS is one of the steps leading to autonomy. Oxford (1990) defines learning strategies as "operations employed by the learner to aid the acquisition, storage, retrieval, and use of information" (p. 8).

According to Gürsoy (2010), LLS research related to children is limited as the previous studies mostly focused on adolescents and adults (see, Halbach, 2000; Green and Oxford, 1995; Griffiths and Parr, 2001; Kirsch, 2008; Sheorey, 1999). Purdie and Oliver (1999) argue that there are social and psychological differences between adults and YLs, thus they point to the fact that the results of LLS research with adults cannot be applied to children. The limited number of LLS research with YLs is mostly conducted in ESL (English as a Second Language) contexts. Hsiao and Oxford (2002) stresses the importance of recognizing differences in SL and FL settings. In addition, in their study Green and Oxford (1995) argue that strategy use of students might show variety depending on their learning environments. Limited number of research on bilingual children (see, Purdie \& Oliver, 1999), immersion (see, Chamot \& El-Dinary, 1999), and ESL contexts points out to the need to extend strategy research on YLs. Therefore, there is a need for studies conducted with children in EFL (English as a Foreign Language) environments. Furthermore, earlier studies either focused on a single strategy type (cognitive, social, etc.) or strategies used while performing a single skill (reading, speaking, etc.) (Gürsoy, 2010). Hence, there is a need for a more comprehensive study.

It is no doubt that taxonomies and inventories are wonderful tools to identify LLS. However, earlier taxonomies and inventories developed so far involved older learners' (adolescents and adults) LLS. The only LLS taxonomy for children is developed by Gürsoy (2010) by collecting data from 9-11 year children in Turkey.

Many researchers have developed their own inventories for older learners (adolescence + ) according to their own classification of LLS (see Bialystok, 1978; Carver, 1984; Naiman, Frochlich, Stern, \& Todesco 1978; O'Malley and Chamot, 1990; Rubin, 1981; Weinstein \& Mayer, 1986). However, most of these lack reliability and validity tests. SILL (Strategy Inventory for Language Learning) that is developed by Oxford (1990), is one of the instruments that were tested for its reliability and validity. LLS that are in the inventory cover four basic skills: reading, writing, speaking, and listening. The strategy descriptions used in SILL are gathered from a taxonomy, which was based on an extensive literature and research review and developed by Oxford, (1990). Strategies are grouped under two main categories as direct and indirect strategies. Direct strategies are those that involve direct use of language as well as affect language learning directly. Whereas, indirect strategies are not involved directly with the language learning, they support it (Oxford, 1990; Hsiao and Oxford, 2002). Each major category consists of three strategy groups: Memory, cognitive, and compensation strategies under direct strategies and metacognitive, affective and social strategies under indirect strategies. These strategy groups are composed of 19 strategy sets. As a whole Oxford's strategy system includes 62 strategies. Since this is the richest and the most detailed system of categorization current study uses it for comparison.

However, SILL is developed for and tested on adolescents and adults and therefore is not appropriate for and applicable to children for two reasons: First, the language of the inventory can be difficult to comprehend for children, even when translated and its validity and reliability is measured. Second, the inventory is developed by using previous data and research results, mostly conducted on older learners and, hence cover strategies used mostly by a specific age group. It is possible that children use different strategies than those listed in the inventory and/or they may not use all strategy types that are used by adults. Therefore, there is a need to develop an instrument to learn about children's LLS in a more practical, reliable, and valid way in order to help children become aware of LLS, enable teachers to learn about their students' strategy types, develop new methodologies or adopt existing ones, aid YLs to become autonomous and self-directed learners, increase the number of strategies that are being preferred and used by children, and implement strategy training. Hence, the current study aims at developing a LLS inventory for children in an EFL context. The study 
is significant as it aims to shed some light to LLS research with children by collecting data from 10-11 year old children learning EFL. What's more, it aims to inquire LLS of YLS as a whole without any specific concentration on a specific strategy type or a language skill.

\section{Method}

The study aims to develop a LLS inventory for EFL children in Turkey. Unlike other inventories in the literature the item pool is formed by data gathered from children in the same context.

\subsection{Subjects}

The research is conducted on 402 fourth and fifth grade students (age 10-11) in four primary schools in Turkey. Incomplete data from 19 students were excluded from the study and data is gathered from the remaining 383 students.

\subsection{Instrument:}

In an earlier study by Gürsoy (2010) the item pool for the inventory was formed by collecting data from 54 third, fourth, and fifth grade primary school children in Turkey via data triangulation. As a result of an open-ended and semi-guided questionnaire, task-based interviews, observations conducted during task-based interviews, interviews designed according to the results of the questionnaire, and classroom observations data indicating children's LLS are collected and used to develop LLS taxonomy for children.

Each strategy identified as a result of the data collection period was put under a certain strategy group such as memory, cognitive, compensation, metacognitive, affective and social, since it is argued by Hsiao \& Oxford (2002) that six-factor strategy classification developed by Oxford (1990) is more consistent with language learners' strategy use. Afterwards, the strategy sets that these strategies belong to are decided. However, although all items are put under one of the strategy sets, it is unavoidable that there might be inter-correlations among strategies (Oxford, 1990; Hsiao \& Oxford, 2002). That is, some strategies placed under a certain set may also be placed under another. As a result, 293 items are listed.

When looking at the strategies under strategy groups it is seen that there are three strategies under memory strategies and one strategy under affective strategies that children said they are using while learning a FL. Although these might be the only strategies that children are actually using there is also some possibility that other memory and affective strategies could not be identified during data collection process. Thus, by using Oxford's (1990) strategy taxonomy the researcher added items that are considered memory and affective strategies and not indicated by the students. In sum, nine memory and seven affective strategies are added and a total of 309 strategies are listed.

All items were written as they were stated by children. To avoid misunderstandings caused by an adult's way of expressing the same idea, statements were kept in their original form as much as possible, unless there were any incomprehensibility. Since the number of the items are too many for the age group of the subjects, similar strategies under the same strategy set is identified and combined to form a single item. This resulted in 109 items.

In order not to affect the reliability of the instrument, none of the strategies were excluded. If done otherwise, the decision to take out some strategies and leave others will be a subjective opinion and would conflict with the idea of data collection. As an unexplored area it is thought that it would be erroneous to make such judgments on children's LLS.

\subsection{Procedure}

109-item questionnaire was given to 10 experts for their opinion to test the face-validity of the instrument. Experts were chosen from the English Language Teaching and Educational Sciences Departments. Consequently, the inventory, which was initially designed as a 5-point likert scale as "I strongly disagree, I disagree, I somewhat agree, I agree, I strongly agree" reduced to 3-point likert scale and the responses were changed and shortened as "yes, sometimes and no". This change was made due to the fact that slight differences in meaning could confuse children (ages $10-11)$ who are not fully developed cognitively and metacognitively and thus, affect the reliability of their answers.

Secondly, in the initial form, the answer sheet was given at the end of the inventory and responses were written only once at the beginning of each section. Students were then asked to mark the number that fits best with their opinion on the answer sheet. Upon experts' suggestions the responses were given next to each item as otherwise would be 
confusing and impractical.

$$
\text { İngilizce'mi ilerletmek için Ingilizce film yada başka programlar izlerim¹. }
$$

Thirdly, some statements were changed according to the experts' advice and an item was removed from the instrument due to redundancy. Thus, the final version of the instrument constituted 108 items. Lastly, some changes were made in the instructions that resulted in shorter and simpler sentences for better understanding.

The instrument was also tested for content validity. Three experts, all of which are English Language Teaching (ELT) Department professors, were asked to rate each item as appropriate or inappropriate for its strategy group (memory, cognitive, compensation, metacognitive, social, and affective) and score the item as "1" for inappropriate or "2" for appropriate according to its the strategy group. Thus, content validity ratio was calculated. All items, except for four items $(58,86,103,107)$, are rated as appropriate for their strategy group. Accordingly, the content validity ratio was found to be $98,78 \%$. The four items were not excluded from the questionnaire as their content validity ratio was $66.67 \%$.

Before conducting the instrument it was pre-piloted on three students from fourth (2) and fifth (1) grades in different schools that carry similar characteristics with the participants selected for the study, to check the comprehensibility of the items, duration of time to finish the instrument, and to take students' emotional temperature such as boredom, confusion etc. As a result, some statements were either changed or reorganized according to these students' suggestions. It took 25-35 minutes to finish the whole instrument by these children. Considering the children's short attention span the questionnaire was decided to be conducted at two different times by dividing the instrument into two as Direct Strategies (Part A) and Indirect Strategies (Part B). Part A consists of 59 items and Part B consists of 49 items.

Secondly, the inventory was also given to an adult to compare time management and get a second view on the comprehensibility of the items. It took 12 minutes for the adult to finish the instrument, less than half the time that took children to complete the inventory, which also indicated that these three children took their time to read and answer each item.

Lastly, after making necessary changes as a result of the feedback gained in these two pre-pilot trials, the instrument was piloted on a class of $4^{\text {th }}$ grade students in a primary school other than those selected for the study. There were two reasons to select this grade level: First, it is possible that they might ask more questions to clarify their comprehension as they are younger, which will enable the researcher to make appropriate changes and improvements on the inventory. Second, it could be a good indicator for the researcher that if this age group (10 year-olds) could complete the instrument and comprehend, it is more likely for an older age group (11 year-olds) to understand and finish the inventory.

\subsection{Data Analysis}

A series of statistical analyses were made on the data. To determine the structure of the instrument "Principle Component Analysis" was made and for this, varimax rotation technique was used. Reliability of the inventory was tested by using test- retest method with 45 randomly selected students in fourth and fifth grades. 10 days were given between first and second application. The relation between the two applications was calculated by using "Pearson Moments Correlation" coefficient for each strategy set (memory, cognitive, compensation, metacognitive, social, and affective) and for the whole instrument. The reliability of the items was tested according to .05 significance level. To determine the items in the instrument item-total correlation coefficients that are above 0.20 , factorial load being 0.40 or higher were used as a criteria, moreover, differences in single factor needed to be carried at least at .1 level. Internal consistency for all sub-groups and the whole instrument, that appeared as a result of construct validity analysis (factor analysis), was calculated by using Cronbach's Alpha formula. Significance level is considered as .05 for all analysis used in the study, others above this level is indicated. Analyses were made by using SPSS program.

\section{Results}

The initial statistical analysis for reliability was done by using Pearson-Moments Correlation technique by using the results gathered from test and re-test. As a result, the answers to 58 items were found to be reliable and 50 items were

${ }^{1}$ I watch movies or programs in English to improve my English. (yes/sometimes/no) 
unreliable. That is, the answers for the 58 items were consistent in the test and the re-test. Therefore, 50 unreliable items were discarded from the rest of the statistical analysis. There might be several reasons for this result. First, the subject group was children who can be distracted easily and lose concentration. It is possible that some of these children might have lost concentration either during the test or the re-test, which in turn affected their choices. Second, as it was indicated by some of the children after the re-test their behaviors in some areas might have changed in 10 days' time. It is possible that the initial application of the inventory might have caused some awareness and encouraged some children to change their behavior. For instance, one student during the re-test said that she was not reading English books and films before, but she had started doing so, thus changed her answer at the re-test. Third, in the initial testing some of the children were not sure about their behaviors and gave conflicting answers in the re-test.

Afterwards, 58-item inventory was tested for construct validity via exploratory factor analysis. Construct validity is related to different traits in a scale, test, and/or questionnaire. One problem related to construct validity is whether a group of items define or comprise a construct. Different correlation techniques such as factorial analysis, multitraitmultidimensional matrix can be used to test the construct validity (Hatch \& Farhardy, 1982).

Factor analysis is a multi-variable statistical procedure that aims to find new dimensions that are few in number and are independent and conceptually meaningful by bringing up number of dependent variables. Exploratory factor analysis aims to find factors by deriving from the relationship between the variables. (Büyüköztürk, 2012, p. 117).

There are several techniques in constructing factors. Principle axes, maximum likelihood, multiple grouping and principle component analysis (PCA) are examples of these techniques. Current study uses Principle Component Analysis (PCA). PCA is a multi-variable statistics that reduces variables and aims to reach meaningful conceptual constructs and it is frequently used in practice and it is respectively easy to interpret (Büyüköztürk, 2012, 118).

In factor analysis there are several criteria to take into consideration when discarding items that do not measure the same construct:

1) Factor loadings of items in a specific factor need to be high. If there is a cluster of items that are highly related to a factor means that these items together measure a concept or a construct. Büyüköztürk (2012), suggest that the minimum value for factor loadings must be 0.30 and that it is a good solution to choose items with factor loadings 0.45 or above. The bigger the variance ratios as a result of the factor analysis, the stronger its factorial structure. It has been suggested that in determining the factors' factorial loading that are between 0.30 and 0.40 can be used as lower limit (Dunteman, 1989; Gorsuch, 1983; Coombs and Schroeder, 1988). In social sciences it is adequate to have variance ratios that are between $40 \%$ and $60 \%$ (Dunteman, 1989; Gorsuch, 1983). Current study discarded items with factor loadings 0.40 and above.

2) Items' factor loading need to be high in one factor and low in the others. Büyüköztürk (2012) argues that the difference between the two factor loadings must be minimum .10. In a multi-factorial construct an item that gives high factor loading in more than one factor is referred to as a colliding item and discarded from the scale.

3) Communalities of items in important factors need to be high. Although Büyüköztürk (2012) claims that it would be a good solution to have communalities above 0.66 , he also argues that this is difficult in practice.

Another point to realize in factor analysis is to decide the number of the important factors that the variables (items of the scale or the questionnaire) measure. Büyüköztürk (2012) lists three criteria. One criterion is to determine factors with eigenvalues 1 or above. This minimum limit can be increased by the researchers.

Another criterion is the total variance. In multi-factor scales high number of factors increases total variance, however, this time it becomes difficult to name each factor. In single-factor scales it might be enough to have a total variance of $30 \%$ or above. In multi-factor scales it is expected to have a higher variance. The bigger the total variance as a result of the factor analysis, the stronger its factorial structure. When total variance increases it means that the construct is measured well. In order to increase total variance, one can increase the number of factors or choose items with higher factor loadings.

Last criterion is the examination of the scree plot, which is drawn according to the eigenvalues. The vertical axis sows the amount of eigenvalues and horizontal axis shows the factors. High velocity decreases show the number of important factors.

The researcher can rotate the factors that s/he gets after factor analysis to interpret the results independently, clearly, and meaningfully. Hatch \& Farhardy (1982) argue that varimax rotation is the most common method, thus, the present study used varimax rotation in the analysis.

In the light of these information 58 items were factor analyzed. The initial analysis resulted with 18 factors with eigenvalues 1 or above. Total variance of these 18 factors was found to be $85.023 \%$. As it was discussed above high 
numbers of factors increases total variance but makes it difficult to name each factor (Büyüköztürk, 2012).

Due to these results, and by examining the scree plot it was decided to do the factor analysis to reduce the factors. As a result of the third factor analysis total variance was found to be $46.001 \%$. This is an acceptable percentage for a multi-factor scale. When rotation component matrix was examined 11 items (A11, B24, B26, B31, C47, C48, C51, C52, D1, D18, E46) needed to be removed according to the criteria mentioned above.

When certain items are discarded it is necessary to continue factor analysis until all conditions are met as factor analysis is a data reduction technique. After conducting the factor analysis for the $11^{\text {th }}$ time total variance increased and approached to $50 \%$ with $49.871 \%$, which is considered high. At the end of the factor analysis 30 items were left from the 58 items and these were distributed to four factors (see Appendix for 30-item CHILLS).

The items were checked for internal reliability by using Cronbach's Alpha. The reliability of the scale was found to be high (.88). Then each factor was tested for internal reliability by using the same technique. Accordingly, the reliability of each factor is as follows: Factor $1=.8491$; Factor $2=.8192$; Factor $3=.7752$; Factor $2=.7852$.

\section{Discussion}

At a glance, children's inventory for language learning strategies (CHILLS) is different from adults' SILL. First of all, instead of six factors there are four factors in CHILLS. Moreover, factor names are different from those of SILL's, as after the statistical analysis the items did not group as memory strategies, cognitive strategies, etc. The first factor consists of strategies for general study habits; second factor includes strategies to improve language learning. Third factor is composed of strategies to facilitate the reception and production of the language. Fourth factor consists of strategies one use to consolidate knowledge in the target language.

First factor is mostly composed of cognitive and metacognitive strategies and two social strategies that children use. The strategies under this group mostly refer to general study habits of children, for instance, using a newly learned vocabulary in context in order to pronounce it correctly, studying ones mistakes/errors after a speaking activity, before speaking in English checking one's background knowledge by examining books, or asking others to correct one's mistakes.

Second group of strategies are mostly used to improve language learning. Although mostly cognitive, there are metacognitive, social and compensation strategies in this group, however, their common property is that they are used to improve learning in the target language. To give some examples; re-reading the books that was read before to improve one's English, using the newly learned vocabulary when speaking with native speakers, using other books or educational CD's to learn more about the language, do practice tests etc.

Third factorial group is composed of strategies that are mostly used for the facilitation of the reception and production of the target language. They are mostly compensation strategies but there are two memory strategies and two cognitive strategies as well. When statements under this group are examined it can be seen that although they call for different types of strategies they are used for the same purpose. For example, keeping new vocabulary in mind by making an association between the pronunciation of two words in English and Turkish such as snake and sinek (a fly), keeping notes of peers' questions after speaking activities, studying by writing in order to pronounce a word correctly, making use of cognates such as leopard and leopar, radio and radyo etc. are all strategies for reception. Using gestures and mimicry when speaking; drawing the picture of an unknown vocabulary when speaking or writing; switching to L1 when speaking are strategies used to facilitate the production of the target language.

The last group of strategies is common in that they are used for the consolidation of the target language. For example, listening to or reading a passage a second time, practicing new information regularly, using extra resources to comprehend, write, listen or speak in English etc. When looking at the results it is clear that children use different strategy groups for their own learning needs, which makes them unique in their strategy preferences and use.

\section{Conclusions}

The main purpose of the study was to develop a scale that can be used by primary school English language teachers to identify their learners' strategies in a much easy, reliable and practical way. At the end of the study a valid and reliable inventory for children's LLS (CHILLS: Children's Inventory for Language Learning) is developed. Individual attempts to inquire LLS with the use of teacher observations of students are inadequate, inconclusive, and not generalizable. Observations provide information only on the observable aspects of strategy use such as cooperating with peers, asking questions for clarification or verification, using gestures and mimicry etc. Other techniques (such as diary keeping, 
interviewing, think aloud protocols etc.) used to identify strategies require a lot of time to gather information and to analyze it. Therefore, a valid and reliable instrument would save teachers a lot of time when investigating their students' strategies.

Moreover, a scale like this enables the teachers to see what types of strategies are preferred most by their group of students just by looking at the points gathered at the end of each part. Thus, this information will enable the teachers to focus and train their students on less frequently used but effective strategies and consequently increase their strategy repertoire.

In addition, by using such an instrument first steps of conducting strategy training and developing autonomous learners will be taken. Appropriate strategy training can be conducted if the learners' needs are taken into consideration to help children become more successful and autonomous language learners.

In many ways current study is unique. First of all, it is the first one that collected data from children in EFL contexts that took all language skills and strategy groups into consideration. Second, unlike others, items of the CHILLS were gathered from subjects via data collection not through literature review. Third, to the author's knowledge it is the first valid and reliable LLS inventory developed specifically for YLS.

The present study sheds some light to LLS research and encourages others to conduct studies on children in other contexts with different L1 and cultural backgrounds. In addition, the current study paves the way for strategy instruction on children and the development of specific approaches to train children learning English. The CHILLS may help ELT teachers in developing their classroom methodologies, finding ways to teach more effectively, understanding children's choice of strategies, designing lessons according to children's needs, helping children learn effective strategies other than their existing ones, implementing strategy training and helping children learn new and effective strategies, creating autonomous learners.

Further research is necessary to identify children's LLS in different EFL contexts to compare any possible strategy preferences resulting from cultural backgrounds, educational settings, educational systems, classroom methodologies etc. Identification of LLS is important to support TEYL (Teaching English to Young Learners), therefore, LLS research with children should be expanded as many countries in Europe and Asia are now lowering the starting age for language learning. Finally, comparative studies in ESL environments are also necessary to identify contextual differences.

\section{Acknowledgement}

The article is derived from an unpublished doctoral dissertation by Gürsoy, E. (2004).

\section{References}

Arkan, A. (2012). Writing. In Gürsoy, E. and Arıkan, A. (Eds.) Teaching English to young learners: An activity-based guide for prospective teachers. Ankara: Eğiten Kitap.

Benson, P. (2001). Teaching and researching autonomy in language learning. England: Pearson Education.

Bialystok, E. (1978). A theoretical model of second language learning. Language Learning, 28, 69-83.

Büyüköztürk, Ş. (2012). Sosyal bilimler için veri analizi el kitabı: İstatistik, araştırma deseni, SPSS uygulamaları ve yorum. Ankara: Pegem Yayıncilik.

Carver, D. (1984). Plans, learner strategies and self-direction in language learning. System, 12, 123-131.

Cohen, A. D. (1990). Language learning: Insights for learners, teachers, and researchers. NY: Newburry House.

Corno, L \& Mandidach, E. B.(1983). The role of cognitive engagement in classroom learning and motivation. Educational Psychologist, 18, 88-108.

Coombs, W. \& Schroeder, H. (1988). An analysis of factor analytic data. Personality and Individual Differences, 9, 79-85.

Council of Europe (2004). European Language Portfolio, Principles and Guidelines. Strasbourg: Language Policy Division.

Dunteman, G. H. (1989). Principle components analysis. Quantitative Applications in the Social Science Series, No. 69. Thousand Oaks, CA: Sage Publications.

Dworetzky, J. P. (1993). Introduction to child development. USA: West Publishing Company.

Enever, J.\& Moon, J.(2009). New global contexts for teaching primary ELT: Change and challenge. In J. Enever, J. Moon, and U. Raman (Eds.), Young learner English language policy and implementation: International perspectives (pp. 5-21). Reading, UK: Garnet Publishing.

Gorsuch, R. L. (1983). Factor analysis. Hillside, NJ: Lawrance Erlbaum.

Green, J. M. and Oxford, R. L. (1995). A closer look at learning strategies, L2 proficiency, and gender. TESOL Quarterly, 29, 261-293.

Griffiths, C. and Parr, J. M. (2001). Language-learning strategies: Theory and perception. ELT Journal, 53,247-54.

Gürsoy, E. (2012a). Theme-based teaching. In Gürsoy, E. and Arıkan, A. (Eds.) Teaching English to young learners: An activity-based guide for prospective teachers. Ankara: Eğiten Kitap. 
Gürsoy, E. (2012b). Music and puppets. In Gürsoy, E. and Arıkan, A. (Eds.) Teaching English to young learners: An activity-based guide for prospective teachers. Ankara: Eğiten Kitap.

Gürsoy, E. (2010). Investigating language learning strategies of EFL children for the development of a taxonomy. English Language Teaching, 3, 164-175.

Gürsoy, E. \& Akın, F. (2013). Is younger really better? Anxiety about learning a foreign language in Turkish children. Social Behavior and Personality: An International Journal, 41, 827-842.

Halbach, A. (2000). Finding out about students' learning strategies by looking at their diaries: A case study. System,28, 85-96.

Halliwell, S. (1992). Teaching in English in the primary classroom. Harlow: Longman.

Hatch, E. \& Farhardy, H. (1982). Research design and statistics for applied linguistics. Rowley, Mass.: Newbury House.

Hsiao, T. Y. and Oxford, R. L. (2002). Comparing theories of language learning strategies: A confirmatory factor analysis. The Modern Language Journal, 86, 368-383.

Johnstone, R. (2009). An early start: What are the key conditions for generalized success? In J. Enever, J. Moon, and U. Raman (Eds.), Young learner English language policy and implementation: International perspectives (pp. 31-41). Reading, UK: Garnet Publishing.

Kirsch, C. (2008). Teaching foreign languages in the primary school. NY: Continuum.

McDonough, S. K. (2001). Promoting self-regulation in foreign language learners. The Clearing house, 74, 323.

Moon, J. (2000). Children learning English. Oxford: Macmillan-Heinemann.

Naiman, N., Frochlich, M., Stern, H. H., \& Todesco, A. (1978). The good language learner. Toronto: Ontario Institute for Studies in Education.

O'Malley, J. M. and Chamot, A. U. (1990). Learning strategies in second language acquisition. UK: Cambridge University Press.

Oxford, R. L. (1990). Language learning strategies: What every teacher should know?. USA: Heinle and Heinle Publishers.

Purdie, N. and Oliver, R. (1999). Language learning strategies used by bilingual school-aged children. System, 27, 375-388.

Rubin, J. (1981). Study of cognitive processes in second language learning. Applied Linguistics, 2, 117-131.

Rubin, J. (1987). Learner strategies: Theoretical assumptions, research history and typology. In A. L. Wenden, \& J. Rubin (Eds.), Learner strategies in language learning (pp. 15-30). UK: Prentice Hall International Ltd.

Sheorey, R. (1999). An examination of language learning strategy use in the setting of an indigenized variety of English. System, 27, 173-190.

Weinstein, C. E. and Mayer, R. E. (1986). The teaching of learning strategies. In . M. C. Wittrock (Ed.), Handbook of research on teaching, 3rd edition. New York: Macmillan Company.

Zhao, N. (2009). Metacognitive strategy training and vocabulary learning of Chinese college students. English Language Teaching, 2 , 123-129.

\section{Appendix}

\section{Children's Inventory For Language Learning Strategies (Chills) ${ }^{2}$ (c) E. Gürsoy}

\section{Name-surname: \\ Date of birth:}

School:

Sex: Girl/Boy

Dear Students,

What do you when learning a foreign language? (What do you do to understand a reading text? How do you learn new vocabulary? What do you do for listening comprehension? etc.). We will be able to understand how you learn English by looking at your responses to the following statements. If you do the behaviors in the items mark "Yes", if you do them from time to time mark "Sometimes" and if you do not do it mark "No" with an "X". Make sure that you respond to every item.

\section{Example:}

Read the item below and put an "X" on the answer that represents your idea best.

I watch movies or programs in English to improve my English. Yes

Sometimes No

You may move to the other items after completing the example.

\section{$\underline{\text { Part A }}$}

2 The original instrument is in Turkish. It is translated by the author to reach the global community. 


1. I try to speak in English with my teacher, friends and parents.
2. In an activity I work with a peer, I share my notes and/or ask her/him the points I don't
understand.
3. After writing or saying something in English I ask my teacher, friend, or someone who is
knowledgeable to correct my errors.
4. I use a new vocabulary in sentence to pronounce it correctly.
5. Before I say something in English I check my book, notebook, etc. to see what we
learned about the topic.
6. I test myself to improve my English.
7. I revise the lesson, the notes I take at school, my old books and notebooks, unknown or
newly learnt vocabulary by reading or writing.
8. I practice with my parents or someone else before speaking activities.
9. I study my errors after speaking activities.
10. When I think that I cannot learn I tell my parents I need help. Ex: Taking private
lessons.

\begin{tabular}{|c|c|c|}
\hline Yes & Sometimes & No \\
\hline Yes & Sometimes & No \\
\hline Yes & Sometimes & No \\
\hline Yes & Sometimes & No \\
\hline Yes & Sometimes & No \\
\hline Yes & Sometimes & No \\
\hline Yes & Sometimes & No \\
\hline Yes & Sometimes & No \\
\hline Yes & Sometimes & No \\
\hline Yes & Sometimes & No \\
\hline
\end{tabular}

\section{Part B}

11. I read the books I read before to improve my English.
12. I use the words I learnt recently when speaking with tourists and native speakers to
pronounce them correctly.
13. I like to use English in fun ways. For example; I try to make jokes in English.
14. To improve my English I work with supporting materials such as books, CDs that
teach English.
15. I do tests to improve my English.
16. While reading I try to guess the unknown structure by comparing it with the one that I
know.
17. Before I write or listen in English I read about that topic, revise the unit, read a similar
paragraph, try to find an example, prepare a draft or make sentences with the topic.
18. While speaking I coin words that might have a similar meaning instead of the one that
I do not know.

\begin{tabular}{|c|c|c|}
\hline Yes & Sometimes & No \\
\hline Yes & Sometimes & No \\
\hline Yes & Sometimes & No \\
\hline Yes & Sometimes & No \\
\hline Yes & Sometimes & No \\
\hline Yes & Sometimes & No \\
\hline Yes & Sometimes & No \\
\hline Yes & Sometimes & No \\
\hline
\end{tabular}

\section{Part C}

19. I try to keep the words in my mind by associating their pronunciation. For example, snake and sinek (a fly).

20. I take notes of unknown words, my peers questions and/or things that I remember after drama activities.

21. I use gestures when I have trouble in explaining meanings of things in English.

22. While writing or speaking I draw the picture of an unknown word.

23. While speaking if I do not know the meaning of a word I say its Turkish and keep on talking.

24. I repeatedly write the new word to be able to say it correctly.

25 . While writing or reading I benefit from cognates to facilitate my writing and reading comprehension. For example; radio, television, leopard, chimpanzee.

\begin{tabular}{|c|c|c|}
\hline Yes & Sometimes & No \\
\hline Yes & Sometimes & No \\
\hline Yes & Sometimes & No \\
\hline Yes & Sometimes & No \\
\hline Yes & Sometimes & No \\
\hline Yes & Sometimes & No \\
\hline Yes & Sometimes & No \\
\hline Yes & Sometimes & No \\
\hline Yes & Sometimes & No \\
\hline
\end{tabular}

26. To facilitate my reading and listening comprehension, writing and speaking I use dictionaries, my course book, notebook or language teaching CDs.

27. I remember a word by thinking its location on a page. 


\begin{tabular}{|c|c|c|c|}
\hline 28. I read or listen to an English text again after reading or listening to it once. & Yes & Sometimes & No \\
\hline $\begin{array}{l}\text { 29. Before writing something I identify the words and structures from my bok and } \\
\text { notebook. }\end{array}$ & Yes & Sometimes & No \\
\hline 30. I revise the new information with regular intervals. & Yes & Sometimes & No \\
\hline
\end{tabular}

\title{
Children's Inventory For Language Learning Strategies (Chills) Developed For Turkish Children Learning A Foreign Language
}

\author{
(c) E. Gürsoy
}

Directions for the Instructor:

This strategy inventory is developed for children in order for them and their instructors to learn about their choice of language learning strategies while learning a foreign language. In the following pages there are 30 statements about learning a new language. Please ask your students to read each statement carefully and mark their answers on the boxes next to the statements.

Students need to be informed that the answers should be given according to how well a statement describes the person answering. Decisions shouldn't be given according to what seems to be true or what somebody else would say true.

\section{Scoring}

First of all scores from each part is calculated. Then, in order to find out the total score each point from the four different parts of the scale is added. Each "yes" is "2", "sometimes" is "1", and "no" is "0" points. Maximum points that can be gathered from the scale is 60.

\section{$\underline{\text { Part A }}$}

1.

2.

3.

4.

5.

6.

7.

8.

9.

10.

Total:

Total:
17.

18.

15.

16.

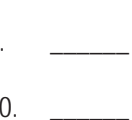

\section{$\underline{\text { Part C }}$}

19.

20.

21.

22.

23.

24.

25.

General Total:
11.

2.

14.

.

-

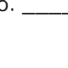

